\title{
Continuity and Access in the Era of Part-Time Practice
}

Thomas Bodenheimer, $M D^{1}$

Cyntbia Had, MD²

Wilhelm Lebmann, $M D^{3}$

${ }^{1}$ Center for Excellence in Primary Care, University of California, San Francisco, California

${ }^{2}$ Family Medicine, University of California, Irvine, California

${ }^{3}$ Aurora Family Medicine Residency

Program, Milwaukee, Wisconsin

Conflicts of interest: authors report none.

\section{CORRESPONDING AUTHOR}

Thomas Bodenheimer, MD

Department of Family and Community Medicine

University of California, San Francisco 995 Potrero Avenue

San Francisco, CA 94110

Thomas.Bodenheimer@ucsf.edu

\begin{abstract}
The number of physicians seeing patients part time is growing, an evolution that challenges the primary care pillars of continuity and access. The growth of parttime practice is a response to burnout and to the pressures facing primary care physicians. Physicians who work fewer clinical hours and thereby reduce burnout are more satisfied with their careers, less likely to leave their jobs, and provide a better patient experience. Primary care practices can make a number of adjustments to optimize continuity and access in this era of part-time practice. Moreover, physicians who work fewer clinical hours are equally capable of fostering trusting relationships with patients as physicians seeing patients full time.
\end{abstract}

Ann Fam Med 2018;16:359-360. https://doi.org/10.1370/afm.2267.

$\mathrm{D}$ ue to the growing number of physicians seeing patients part time, the road to the patient-centered medical home $(\mathrm{PCMH})$ is taking a detour. A major section of National Committee for Quality Assurance (NCQA)'s 2017 PCMH standards is focuesed on patient-centered access and continuity of care. Yet the increasingly part-time nature of medical practice can be a roadblock to both access and continuity.

In $2011,22 \%$ of male physicians and $44 \%$ of female physicians worked less than full time, up from $7 \%$ and $29 \%$ in $2005 .^{1}$ This essay explores ways in which primary care can adjust to the era of part-time practice, seeking to optimize continuity and access and to preserve the trusting therapeutic relationships at the heart of medical practice.

\section{CONTINUITY AND ACCESS}

Interpersonal continuity (patients seeing the same clinician every time they seek care) is associated with greater patient and physician satisfaction, better chronic and preventive care, reduced hospitalization rates, and lower costs. ${ }^{2}$ The majority of patients want the same primary care physician to care for them over time. ${ }^{3}$ In particular, elderly patients, parents of young children, those on Medicare and Medicaid, those with chronic conditions, and those with worse health status value continuity. Young healthy people, in contrast, may prioritize prompt access over continuity. People who value continuity are willing to wait to be seen by their regular physician. ${ }^{3}$

The increase in part-time practice is eroding both continuity of care and prompt access to care. Continuity and patient access to care naturally decline when physicians work fewer hours. ${ }^{4}$ Continuity and access are particularly challenging in some residency teaching practices where faculty and residents may be in clinic only 1 or 2 half-days per week. ${ }^{5}$

\section{WHY PHYSICIAN WORK HOURS ARE DECREASING}

The growth of part-time practice is a response to evolving difficulties in the primary care environment. A full-time primary care physician-working independently of a team and with a typical panel of 2,500 patients-could spend an impossible 21.7 hours each day providing full-spectrum, highquality acute, chronic, and preventive care. ${ }^{6}$ The electronic medical record has increased total work time while reducing time spent with patients, contributing to the growing prevalence of health professional burnout. ${ }^{7}$ The 
concept of "primary care do-ability" has surfaced in the literature ${ }^{8}$ and full-time primary care practice is becoming less do-able. Reducing work hours is a common response to physician burnout. ${ }^{9}$

Physicians working fewer clinical hours are more satisfied with their careers and less likely to leave their jobs. ${ }^{10}$ Although these physicians may have worse continuity and access, they appear to provide a better patient experience. ${ }^{4}$ Perhaps patient satisfaction is more strongly influenced by the negative impact of burnout than the positive impact of continuity.

\section{ADDRESSING THE REALITY OF PART-TIME PRACTICE}

Although the benefits of continuity of care and prompt access to care are undeniable, reducing the work hours of primary care physicians has merit-including for patients - and appears to be an unstoppable trend. Possible strategies for primary care to optimize continuity and access in the era of part-time practice include:

- Provide work options for physicians to maximize continuity and access. For example, it is a problem if half-time primary care physicians work Mon-Tue-Wed and are unavailable the remainder of the week. Preferably, half-time physicians could work 1 full day and 3 half-days per week or even 5 half-days per week and thus be accessible to their patients 4 or 5 weekdays.

- Negotiate policies with part-time physicians requiring them to read and answer e-mails from patients and practice staff daily, recognizing that continuity of care and access need not involve face-to-face visits.

- Develop guidelines allowing staff to reach physicians with patient questions on nonclinical days.

- Create job-sharing arrangements with another part-time physician, so that the 2 physicians are jointly responsible for and familiar with a full panel of patients. The patients would understand that they will see either their personal physician or 1 other physician.

- Match a full-time nurse practitioner or physician assistant to comanage the panels of part-time physicians so that patients will see either their personal physician or the mid-level clinician on their team. This and the previous strategy redefines interpersonal continuity of care as patients see 1 of 2 practitioners.

- Educate new and existing patients about the value of continuity and how to maximize use of the system.

- Advocate that health systems adapt their contracts to allow benefits for physicians working fewer clinical hours to avoid health systems losing physicians due to burnout and having difficulty replacing them.

Although this essay focuses on the important and measurable primary care attributes of continuity and access, the bedrock of primary care lies deeper than those attributes: a trusting therapeutic relationship between physicians - and the care teams surrounding them-and patients. Patients want several things from their physicians, including medical competence ("I want my physician to have the knowledge needed to help me"), empathy ("I want my physician to care about me"), and familiarity ("I want to know my physician and I want my physician to know me").).112 Physicians seeing patients part time are equally capable of fostering such relationships as physicians in full-time clinical practice. To harmonize part-time practice with patient-centered care, physicians should pay close attention to the patient concerns of competence, empathy, and familiarity.

The world of part-time practice is here to stay. The patient-centered medical home can adopt strategies to optimize continuity and access, and deepen trusting patient-physician relationships, in the part-time era.

To read or post commentaries in response to this article, see it online at http://www.AnnFamMed.org/content/16/4/359.

Key words: continuity of care; access to health care

Submitted October 18, 2017; submitted, revised, January 5, 2018; accepted January 19, 2018.

\section{References}

1. Satiani B, Williams TE, Brod H, Way DP, Ellison EC; American Group Management Association. A review of trends in attrition rates for surgical faculty: a case for a sustainable retention strategy to cope with demographic and economic realities. J Am Coll Surg. 2013; 216(5):944-953, discussion 953-954.

2. Saultz JW, Lochner J. Interpersonal continuity of care and care outcomes: a critical review. Ann Fam Med. 2005;3(2):159-166.

3. Pandhi N, Saultz JW. Patients' perceptions of interpersonal continuity of care. J Am Board Fam Med. 2006;19(4):390-397.

4. Panattoni L, Stone A, Chung S, Tai-Seale M. Patients report better satisfaction with part-time primary care physicians, despite less continuity of care and access. J Gen Intern Med. 2015;30(3):327-333.

5. Bodenheimer T, Gupta R, Dube K, et al. High-Functioning Primary Care Residency Clinics. Washington, DC: Association of American Medical Colleges; 2016. www.aamc.org/buildingblocksreport.

6. Yarnall KSH, Østbye T, Krause KM, Pollak KI, Gradison M, Michener JL. Family physicians as team leaders: "time" to share the care. Prev Chronic Dis. 2009;6(2):A59.

7. Sinsky C, Colligan L, Li L, et al. Allocation of physician time in ambulatory practice: a time and motion study in 4 specialties. Ann Intern Med. 2016;165(11):753-760.

8. Willard-Grace R, Dubé K, Hessler D, et al. Panel management, team culture, and worklife experience. Fam Syst Health. 2015;33(3): 231-241.

9. Shanafelt TD, Mungo M, Schmitgen J, et al. Longitudinal study evaluating the association between physician burnout and changes in professional work effort. Mayo Clin Proc. 2016;91(4):422-431.

10. Linzer M, Levine R, Meltzer D, Poplau S, Warde C, West CP. 10 bold steps to prevent burnout in general internal medicine. J Gen Intern Med. 2014;29(1):18-20.

11. Detsky AS. What patients really want from health care. JAMA. 2011; 306(22):2500-2501.

12. Safran DG. Defining the future of primary care: what can we learn from patients? Ann Intern Med. 2003;138(3):248-255. 